\title{
El ENSAYO: DE LA RETÓRICA RESTRINGIDA A LA RETÓRICA DE LA ARGUMENTACIÓN
}

\author{
Andrés Felipe Peralta Sánchez, $\mathrm{PhD}^{1}$ \\ Pensacola State College.
}

\section{Resumen}

El filósofo Chaïm Perelman (1977) afirma que la aplicación de su nueva retórica a los diferentes discursos y textos argumentativos se traduciría en el desarrollo de retóricas particulares para cada uno de ellos, según el tipo de auditorio al que se dirigen y de la disciplina en la que se practican (p. 19). A partir de esta premisa, nos acercaremos a la retórica del ensayo vista como una teoría particular de la argumentación ensayística que resulta de la aplicación de la nueva retórica de Perelman a este género literario. Sostendremos que dicha aplicación confirma el protagonismo de la argumentación en su estructura composicional y finalidad comunicativa, superando así las limitaciones de la visión restringida de la retórica que sólo considera el elemento estilístico de este tipo de textos.

Palabras clave: retórica, argumentación, ensayo, teoría del ensayo

The essay: restricted rhetoric to argumentation rhetoric

\begin{abstract}
Philosopher Chaim Perelman (1977) affirms that the application of his New Rhetoric to different discourses and argumentative texts will result in the development of specific rhetorical theories for each, according to the kind of audiences they address and the disciplines in which they are practiced (p.19). From this standpoint, we approach the rhetoric of the essay, seen as a specific theory of argumentation in the essay resulting from the application of Perelman's New Rhetoric to this literary genre. We argue that this application confirms the leading role of argumentation in its compositional structure and communicative aim, exceeding the limitations of a restricted vision of rhetoric that only considers the stylistic aspect of these kinds of texts.
\end{abstract}

\footnotetext{
${ }^{1}$ El presente artículo es una adaptación del capítulo 3 de mi tesis doctoral. La argumentación en los ensayos de William Ospina (2014), disponible en el archivo digital de la Universidad de Ottawa: https://www.ruor.uottawa.ca/handle/10393/31529
} 
Andrés Felipe Peralta Sánchez

Keywords: Rhetoric, Argumentation, Essay Theory

\section{La nueva retórica y la retórica restringida}

La renovación de la retórica mediante la restitución de sus propiedades argumentativas y su transformación en una teoría general de la argumentación son las consecuencias más importantes del proyecto del filósofo belga Chaïm Perelman, quien lleva a cabo una crítica de la concepción de racionalidad heredada de la modernidad cartesiana y de los desarrollos matemático-formales de la lógica convertidos en el paradigma de esta disciplina en el siglo $\mathrm{XX}$ a partir de las teorías de Gottlob Frege.

El desarrollo de un arquetipo matemático-formal de la razón a partir de la noción de evidencia conduce, en la primera mitad del siglo $\mathrm{XX}$, a reducir la esfera del conocimiento a aquellas proposiciones cuya verdad o falsedad puede establecerse ya sea por métodos empíricos que se inspiran de las ciencias naturales, ya sea por deducciones matemáticas a partir de principios claros y evidentes (Perelman y Olbrechts-Tyteca, 2000, pp. 1-3). La racionalidad, definida de acuerdo con estos principios propios del positivismo lógico - filosofía reinante durante la época-, no admite la posibilidad de justificar racionalmente las opiniones y acciones de la vida práctica, abandonando al mito, al relativismo, a la convención y a la violencia importantes áreas de la vida en sociedad como el arte, el derecho, la política y la ética (Perelman, 1977, pp. 8-9). Perelman había sido entrenado en la tradición filosófica del positivismo lógico y había estudiado en detalle el inventario de los procedimientos lógicos de justificación de las proposiciones matemáticas de Frege. Inspirándose en este proyecto descriptivo y en la taxonomía propuesta por este matemático, el filósofo belga decide emprender una investigación que tiene por objetivo recopilar y sistematizar los procedimientos mediante los cuales se pretenden hacer valer nuestras opiniones en debates que involucran valores y preferencias (Perelman, 1977, pp. 9-10).

La descripción y clasificación de dichos procedimientos en controversias filosóficas, legales y políticas conduce a Perelman a concluir que dicha lógica no existe y que los procedimientos que buscan la aprobación de una tesis en la asamblea política, el foro judicial, la 
discusión filosófica, la publicidad y tantos otros foros de debate, no se ciñen a los modelos inductivos y deductivos del positivismo, sino que son mejor caracterizados por una antigua técnica del discurso persuasivo ignorada durante mucho tiempo por la filosofía: la retórica (Perelman, 1977, pp.10-11). ${ }^{2}$ La utilidad cívica y los principios fundamentales de esta técnica fueron establecidos en la Antigüedad por Aristóteles, pero habían sido olvidados debido a que su dimensión argumentativa se había transferido a la lógica (también llamada dialéctica en la Edad Media), reduciendo la retórica a un estudio de la elocuencia y de las figuras de estilo, restringiéndola al arte del ornato y del buen decir, a la vez que se le alejaba de la lógica y de la filosofía. ${ }^{3}$ Es así como el paso de la lógica a la retórica en el proyecto de Perelman conecta su crítica del positivismo con una revisión de la historia de la retórica. ${ }^{4}$

Perelman suma su voz a la crítica de esta historia de la reducción de la retórica a un arte del buen decir a partir de la Edad Media a las de otros pensadores entre los que incluye a Genette, Ricoeur y Barthes (Perelman, 1997, pp.11-15). A la consecuentemente denominada "retórica restringida" -rhétorique restreinte en el texto original de L'Empire rhétorique-, Perelman y su colaboradora, Lucie OlbrechtsTyteca, opondrán una nueva retórica que se reclamará heredera de la retórica de Aristóteles, disciplina en la que el estagirita presenta su doctrina de las técnicas persuasivas utilizadas en la discusión y en el discurso cívico. El nuevo modelo se inspirará, tal como lo había hecho la retórica antigua, de las deliberaciones judiciales en lugar de apelar a

2 'Nous constations que, dans les domaines où il s'agit d'établir ce qui est préférable, ce qui est acceptable et raisonnable, les raisonnements ne sont ni des déductions formellement correctes, ni des inductions, allant du particulier au général, mais des argumentations de toute espèce, visant à gagner l'adhésion des esprits aux thèses qu'on présente à leur assentiment." (Perelman, 1977, pp. 10-11).

${ }^{3}$ En el primer capítulo de L’Empire rhétorique, titulado Logique, dialectique, philosophie et rhétorique, Perelman relata cómo las relaciones entre las tres partes del Órganon aristotélico (Analítica, también llamada Lógica, Dialéctica y Retórica) son modificadas en detrimento de la retórica. Petrus Ramus organiza el estudio de las artes liberales durante la Edad Media, dividiéndolas en gramática, lógica (en adelante fusionada con la dialéctica) y retórica. Mientras que la lógica/dialéctica estudia las reglas del razonamiento y la deliberación, la retórica, que de acuerdo con Aristóteles también debía encargarse de la deliberación de un orador en el foro, la asamblea y las grandes ceremonias cívicas, queda reducida a un estudio del estilo.

${ }^{4}$ Una explicación más detallada de este proceso se puede consultar en Perelman (1991) "Pierre de La Ramée et le déclin de la rhétorique." 
las demostraciones matemáticas, pero extenderá su campo de aplicación a todos los fenómenos argumentativos. ${ }^{5}$

El Traité de l'argumentation: la nouvelle rhétorique, publicado originalmente en 1958, es el texto base en el que Perelman y OlbrechtsTyteca exponen la renovación de la retórica aristotélica como técnica de justificación de los juicios de valor en controversias éticas, estéticas y políticas, y en el que la oponen a una concepción restringida que la confinaba al estudio de las figuras de estilo. ${ }^{6}$ De este modo, la nueva retórica se presenta como una teoría general de la argumentación que abarcaría todos los campos de la vida práctica donde la lógica formal sería insuficiente para explicar los procedimientos de justificación y elección entre varias opiniones probables:

En considérant que son objet est l'étude du discours non-démonstratif, l'analyse des raisonnements qui ne se bornent pas à des inférences formellement correctes, à des calculs plus ou moins mécanisés, la théorie de l'argumentation conçue comme une nouvelle rhétorique (ou une nouvelle dialectique) couvre tout le champ du discours visant à convaincre ou à persuader, quel que soit l'auditoire auquel il s'adresse, et quelle que soit la matière sur laquelle il porte. On pourra compléter, si cela paraît utile, l'étude générale de l'argumentation par des méthodologies spécialisées selon le type d'auditoire et le genre de discipline. C'est ainsi que l'on pourrait élaborer une logique juridique ou une logique philosophique, qui ne seraient que des applications particulières de la nouvelle rhétorique au droit et à la philosophie. (Perelman, 1977, p. 19)

La extensión ganada por la nueva retórica, al asignarle el estudio de todo tipo de discursos y textos que pretendan persuadir o convencer

\footnotetext{
${ }^{5}$ Michel Meyer explica que la retórica nace como una técnica del discurso persuasivo con la finalidad de lograr la restitución de bienes y derechos de los ciudadanos en los procesos judiciales que se dan con la caída de los tiranos en varias ciudades-estado y el restablecimiento de la democracia. La retórica tiene entonces, desde el principio, una vocación práctica y una conexión con el derecho (Meyer, 1991, pp. 9-11). En la historia contemporánea de la retórica, Toulmin (2003), considerado junto con Perelman como refundador de la retórica y de la argumentación en el siglo XX, se inspira igualmente del modelo judicial de la retórica antigua e incluso declara que: "Logic (we may say) is generalized jurisprudence. Arguments can be compared with law-suits, and the claims we make and argue for in extra-legal contexts with claims made in the courts, while the cases we present in making good each kind of claim can be compared with each other" (p. 7).

${ }^{6}$ Para nuestra exposición de los conceptos fundamentales de la nueva retórica nos hemos servido de L'Empire rhétorique : Rhétorique et argumentation (1977), en el que Perelman actualiza y resume el Traité de l'argumentation.
} 
a cualquier audiencia o lector en cualquier debate, la identifica con el término argumentación al tiempo que la diferencia de las demostraciones formales. La nueva retórica o teoría de la argumentación tiene a su cargo las estrategias por medio de las cuales se busca reforzar o incitar la adhesión de una audiencia a las tesis que le son presentadas. En palabras de sus autores: "le but d'une argumentation n'est pas de déduire les conséquences de certaines prémisses, mais de provoquer ou d'accroître l'adhésion d'un auditoire aux thèses qu'on présente à son assentiment" (Perelman, 1977, p. 22). La argumentación no es un proceso abstracto, sino que requiere desarrollarse dentro de un marco textual (el ensayo, el tratado, el artículo, etc.) o discursivo (la oratoria judicial, el sermón religioso, etc.), haciendo necesario establecer retóricas particulares de cada forma textual y oratoria según el tipo de audiencia a la que se dirigen y de disciplina en la que se practican.

\section{La nueva retórica y la retórica del ensayo}

La retórica del ensayo es una de las disciplinas en donde la nueva retórica ha sido utilizada con el fin de explicar tanto la construcción como la finalidad argumentativa de este género literario. La conexión entre el ensayo y la nueva retórica se da con la aparición de varias tipologías y metodologías de análisis en los trabajos de críticos como Terrasse, Vigneault, Angenot y Arenas Cruz que se inscriben dentro del debate siempre vigente sobre la naturaleza literaria del ensayo y que combinan elementos de la nueva retórica con otros provenientes de la retórica antigua.

Jean Terrasse afirma que el ensayo es una obra de arte porque expone explícitamente o implícitamente su retórica además de servirse de ella para hacer que el lector perciba la realidad desde un ángulo literario. ${ }^{7}$ El ensayo literario posee para este estudioso una pretensión a la verdad que no se queda en la mera opinión pero que tampoco renuncia a la subjetividad. De este modo el ensayo se define como:

\footnotetext{
${ }^{7}$ « L'essai appartient incontestablement à la littérature, si comme le veut Paul de Man, le langage littéraire "signifie implicitement ou explicitement sa manière dêtre rhétorique ». La rhétorique de l'essai fait participer le lecteur à une expérience globale dans laquelle la réalité est perçue comme littéraire ; elle l'intègre au contexte à propos duquel l'auteur a décidé de dire quelque chose, tout y étant lui-même engagé » (Dumont, 2003, p. 115).
} 
...le produit d'une tension entre deux désirs apparemment contradictoires: décrire la réalité telle qu'elle est en elle-même et imposer un point de vue sur elle. L'essayiste tente de concilier l'en soi et le pour soi, revendique la praxis comme condition de la manifestation de l'être. Pour lui, le réel n'existe que comme expérience, l'auditoire auquel il s'adresse est le lieu où elle se fait jour. Sa démarche est métaphysique, ce qui explique qu'il ne puisse ni se passer ni se satisfaire du concept. (Dumont, 2003, p. 115)

Este género está emparentado con la retórica porque ambos tienen una perspectiva persuasiva que se dirige hacia lo razonable, desenmascarando los sofismas (p. 119). El ensayo invita al juicio y al compromiso con el autor mediante la persuasión y el convencimiento que son el producto de la argumentación por entimemas o ejemplos, siempre dirigidos a un destinatario. En cuanto a las diferentes formas que toman los ensayos y su relación con los géneros de la retórica, Terrasse afirma que los ensayos analíticos y filosóficos pertenecen al tipo de discurso que Aristóteles llama deliberativo mientras que los escritos polémicos y autobiográficos ocupan el lugar respectivamente de la oratoria judicial y epidíctica, matizados por la presencia de los elementos referenciales que explicarían las tendencias poéticas, narrativas o dramáticas de ciertos ensayos (p.125). Terrasse no da más detalles acerca de la identificación entre géneros retóricos y tipos de ensayos o sobre las tendencias de ciertos ensayos a parecerse a uno u otro género de la literatura. Frente a lo anterior, nosotros creemos que, en lugar de asumir esta tipología que nos parece un poco rígida, es preferible estudiar los diferentes tipos de ensayos a partir del imperativo retórico de adaptación al auditorio y del cumplimiento de la finalidad persuasiva del ensayo, que tanto la nueva retórica como Terrasse reconocen.

Otras retóricas del ensayo influidas por Perelman son la del analista del discurso Marc Angenot y la del crítico Robert Vigneault quienes sostienen una discusión sobre el carácter polémico del ensayo.Para Angenot, el ensayo hace parte del discurso de opinión pero no del polémico. Su tipología del ensayo es el fruto de una aproximación indirecta a sus formas tipo dentro del marco general de una reflexión sobre el panfleto. La tipología de Angenot es influida por la teoría del 
ensayo de Ludwig Rohner que Angenot reelabora en su distinción entre ensayo diagnóstico y el ensayo meditación. El primero, también llamado ensayo cognitivo, es « un discours qui cherche à prendre en charge et à poser en termes de relations un ensemble d'objets notionnels, sans critique du mode d'appréhension qui détermine leur organisation. Il s'agit d'occuper un certain espace idéologique et d'en stabiliser les éléments » (Dumont, 2003, p. 139). El ensayo cognitivo es parcialmente demostrativo y no informativo. La argumentación no hace parte de ninguna polémica y cumple la función didáctica de hacer comprender la ley que rige a la totalidad estable y cerrada de elementos que constituyen su universo.

El ensayo cognitivo y el ensayo meditación corresponden a dos polos del discurso reflexivo y se identifican con la distinción hecha por Ludwig Rohner entre Tesis y Ensayo. Sin embargo, Angenot argumenta que la Tesis o ensayo diagnóstico también posee, a diferencia de lo afirmado por Rohner, un valor literario, pues compensa su insuficiencia teórica mediante un suplemento estético. Lo que sucede en realidad es que el ensayo didáctico se rige por la "rhétorique du constant" ( $\mathrm{p}$. 142), pretendiendo legitimarse a través de una supuesta neutralidad enunciativa que supondría un sometimiento a la fuerza del objeto o de las ideas. El ensayo diagnóstico opera una manipulación ideológica a través de procedimientos retóricos como la desaparición u ocultamiento del enunciador, la subordinación del sujeto lógico del discurso y la formación de pares axiológicos puros (p. ej. el espíritu solitario vs. las multitudes) (p. 147), que lo acercan al panfleto. Así, son rasgos esenciales del ensayo diagnóstico, presentes también en el panfleto « Une même propension à se placer du point de vue de la généralité, jointe à un effacement de l'énonciateur dans le message... » (p. 149). Esta retórica de la disimulación del ensayo diagnóstico evita el debate al tiempo que el argumento por sorites caracteriza su cohesión. Al contrario, el ensayo meditación avanza por el juego de las interrogaciones, ensanchando en cada una el campo de su problemática (p. 149). Aunque pretende la neutralidad, el ensayo diagnóstico es subjetivo y doxológico puesto que « il se veut le résultat dominé d'une méditation qui s'est donnée à elle-même des objets »(p. 150). Cinco marcas retóricas permiten 
reconocer este grado doxológico: la desaparición (effacement) del enunciador; la reducción del discurso a una relación metafórica y débil de abstracciones; la conversión de todo enunciado en un juicio de valor; el carácter axiomático del discurso que niega el juego dialéctico y la puesta en evidencia de sus presupuestos; y finalmente, el numeroso uso de metáforas fijas, especialmente espaciales, que se convierten en los límites de las opiniones expresadas por el autor (p. 152).

De acuerdo con Angenot, muchos ensayos cognitivos son en realidad panfletos disimulados que se ocultan bajo un lenguaje institucional a pesar de haber perdido su fuerza persuasiva. Se trata, en todo caso, de discursos que evitan la polémica (p. 153). El panfleto que se disfraza en ensayo diagnóstico combina siempre el resentimiento y el profetismo que caracterizan a ese género.

El ensayo meditación, segunda forma de la tipología, se opone diametralmente al ensayo diagnóstico. Se trata de « une pensée en train de se faire » (p. 154). El ensayo meditación, en tanto género deliberativo interior (genre délibératif intérieur), hace parte de la tradición literaria. Su técnica expresiva es zigzagueante, avanzando a través de lo accesorio. En él, la imagen intuitiva es superior al silogismo y su desarrollo es con frecuencia riguroso pero subterráneo (p. 155). El ensayo meditación posee las virtudes de: describir los mecanismos del pensamiento en su apropiación de sus objetos; ser discontinuo y aprehender el origen del saber desde la intuición; y presentar a un YO omnipresente como unificador y conciencia de sus límites. Se trata de un discurso aporético en el que la demostración posee una poderosa carga afectiva. Finalmente, se diferencia del panfleto en que este último nunca presenta un pensamiento en construcción sino que se asume dueño de la verdad mientras que el ensayo meditación parte de la experiencia vivida en busca de la verdad (p. 157).

Angenot identifica la retórica con el estilo haciendo de esta un criterio de literariedad y define la retórica en un sentido negativo identificándola con los procedimientos de estilo y de organización del texto que ocultan la ausencia de espíritu crítico y la posible manipulación del lector en el ensayo de tipo diagnóstico que, según el crítico literario belga, es un tipo de ensayo que persuade o aumenta la 
adhesión previa de los lectores con las tesis del escritor, pero que no cuestiona sus propios fundamentos. El ensayo diagnóstico es un tipo de ensayo a evitar desde la perspectiva de Angenot y también desde la nuestra debido a su carácter aparentemente didáctico que tras su estilo oculta rasgos panfletarios y cuestionables estrategias retóricas y argumentativas como el sorites, además de dejarse llevar por una vocación profética que clausura el debate con el lector. Aquí nos importa reiterar que nuestra definición de la retórica no la identifica únicamente con los procedimientos que ocultan la ausencia de una argumentación sino también con aquellos que la favorecen. Desde nuestra perspectiva, los tipos ideales de Angenot ejemplificarían correspondientemente el tipo ideal de ensayo y de argumentación críticos y razonables, así como sus contrarios: el ensayo meditación encarnaría no sólo al verdadero ensayo sino también un ideal de argumentación razonable, mientras que el ensayo diagnóstico sería a la vez un panfleto disfrazado y también un límite del proceder retórico reprobable que esconde la sinrazón y el dogmatismo de las opiniones presentadas.

Robert Vigneault, ataca la tipología de Angenot a partir de la noción musical de registro: "caractères particuliers, "tonalité" propre (d'une œuvre, du discours)" (Dumont, 2003, p. 232) que privilegiaría el rasgo más característico y esquivo del ensayo: su tonalidad, indisociable tanto de la forma como del contenido informado por su escritura. El ensayo escoge un recorrido libre que se caracteriza por los cambios de tonalidad (p. 233). Sus diversos registros se diferencian unos de otros por el grado y modo de presencia del sujeto en la enunciación del discurso. El ensayo "se veut un discours d'un sujet plein" (p. 233) bajo cuatro registros: 1. El registro polémico, que se caracteriza por la presidencia textual (présidence textuelle) del sujeto, que busca un efecto persuasivo mediante el uso del razonamiento eficaz. 2. El registro introspectivo, donde el enunciador es sujeto y objeto del discurso: "le texte se fait discours du sujet" (p. 234) guiado por la confidencia íntima. 3. El registro cognitivo, donde el sujeto de la enunciación se oculta para poner en primer plano al pensamiento enunciado. Se diferencia del tratado por su relatividad personal, fuerte o débil (p. 236). 4. El registro absoluto, que acentúa los rasgos del cognitivo: “L'énonciateur n'est 
plus que simple relais d'un discours qui parle à travers lui, celui d'un sujet transcendantal ou "hyperonymique"..." (p. 237). Estos registros no son categorías absolutas. Gracias a los cambios de tonalidad, es posible encontrar diferentes registros en un mismo ensayo. Vigneault critica a Angenot porque éste ubica el discurso polémico en la ensayística (discurso persuasivo), pero lo excluye del ensayo al separarlo de los discursos agonísticos (literatura de combate). Vigneault propone sumar el registro polémico a las categorías de Angenot y distinguirlo del panfleto. El panfleto varía en contenido respecto del ensayo; es un escrito de circunstancia que se realiza a sí mismo en la acción inmediata propuesta en sus líneas (p. 243). El ensayo, en cambio, posee un carácter recesivo esencial (p. 246). Mientras que el ensayo busca la verdad, el panfleto la asume como su posesión. El ensayo relativiza; el panfleto totaliza y cierra el debate (p. 247).

Nosotros pensamos que la noción de registro ayuda en efecto a matizar la caracterización de Angenot. Pero al concentrarse en el sujeto enunciador no tiene en cuenta que éste está obligado, si quiere comunicar su mensaje, a adaptarse en cada ocasión al auditorio o lector. Si bien los registros son flexibles y permiten su combinación en la estructura un mismo ensayo, estos también podrían caracterizarse desde la perspectiva de la nueva retórica a partir de los diferentes tipos de auditorios a los que un determinado texto o discurso se dirige. Por ejemplo, el adversario es el auditorio del registro polémico, el ensayista que reflexiona sobre sus propias ideas es el auditorio del discurso meditativo o introspectivo, mientras que los auditorios especializados o el auditorio universal podrían caracterizar mejor los registros cognitivo o absoluto. En cuanto a la discusión a propósito de las diferencias entre panfleto y ensayo, a pesar de sus diferencias, compartimos con ambos autores la distinción que llevan a cabo entre el primero como género preponderantemente ideológico que se agota en la acción inmediata, mientras que asignan para el segundo un papel crítico y reflexivo.

Los estudios de Terrasse, Vigneault y Angenot son importantes para entender la retórica argumentativa del ensayo porque sus acercamientos retóricos y las tipologías que de estos se desprenden reconocen la tensión existente en este género entre una tendencia a la argumentación 
y el razonamiento crítico y otra a la declaración dogmática. Lo anterior determina a su vez la construcción retórica del ensayo, incluida su argumentación, su relación con otros géneros vecinos (la tesis, el panfleto, la poesía, la narración, etc.) y el rechazo de una disociación absoluta entre un texto enteramente dogmático y otro completamente abierto y sin presupuestos. Vale la pena resaltar cómo esta tensión es asumida en las reflexiones de ensayistas contemporáneos en español. A modo de ilustración, tenemos el caso de William Ospina, quien reconoce en Los nuevos centros de la esfera que en sus ensayos “... conviven momentos de reflexión serena con apasionadas tomas de partido frente a los rostros conflictivos de nuestra época,..." (2001, p. 12). Y nuevamente, a propósito de la heterogeneidad de la forma ensayo, Ospina declara en La herida en la piel de la diosa que: "El ensayo tiene el deber de huir de la especialización y de la monotonía" y que "estos textos procuran pensar, pero no se limitan a hacerlo. No esquivan el sueño, la especulación, el delirio, (...) más de una vez quisieran ser relatos, ser poemas" (2003, p. 9). De este modo, la investigación sobre los méritos de la argumentación ensayística es indirectamente una determinación del tipo o los tipos de ensayos posibles. Así, el análisis de las técnicas argumentativas en el ensayo nos permitiría también pronunciarnos sobre la proximidad o distancia de un ensayo concreto con los modelos o antimodelos del ensayo como forma a los que hemos pasado revista en las páginas anteriores. Otra perspectiva teórica afín a las ya mencionadas es la de la española Arenas Cruz, autora de la obra reciente más importante sobre la argumentación y la retórica en el ensayo. Esta académica define simultáneamente la retórica como "modelo semiótico de construcción textual y como teoría general de la argumentación", situando su actividad dentro de la estructura del texto ensayístico mediante la tipología de las técnicas argumentativas y los puntos de partida de la argumentación de Perelman y Olbrechts-Tyteca (Arenas Cruz, 1997, p.133ss.). Su argumento es a la vez histórico y formal pues reconoce que, desde la Antigüedad, la retórica fue concebida por Aristóteles y por otros pensadores clásicos como "modelo general de producción de textos y como instrumento de análisis textual" (p. 133). Sobre la Historia de las relaciones entre retórica y argumentación señala que: 
...aunque con importantes variaciones y transformaciones, ciertos principios retóricos relativos a la invención de los argumentos, su estructuración y disposición y su manifestación expresiva, han permanecido vigentes y como telón de fondo en la construcción textual de dichas clases de textos (los textos argumentativos) en todas las épocas, incluido el ensayo moderno. (p. 134)

Arenas Cruz establece la construcción del texto ensayístico a partir de las categorías de la retórica clásica inventio, dispositio y elocutio -dejando por fuera memoria y actio, dirigidos al discurso oratorioy añadiendo una sección sobre los sujetos de la comunicación en el ensayo. Su estudio de la inventio (llamada por la autora nivel semánticoinventivo) se divide en dos secciones: una sobre el referente del ensayo (p. 160ss.) y otra sobre su superestructura argumentativa, que se identifica con la estructura de la retórica clásica: exordio, narración, argumentación, epílogo, siendo la argumentación la parte más importante (p. 181ss.). En ambas secciones, tanto los puntos de partida como las diferentes técnicas de la argumentación son extraídos de la teoría de Perelman y Olbrechts-Tyteca. Arenas Cruz se vale entonces de la nueva retórica para describir el componente argumentativo de la estructura del ensayo convirtiéndola en el marco dentro del cual la argumentación tiene lugar en este género. Siguiendo el modelo de Arenas Cruz, la adaptación de las categorías de la nueva retórica al estudio de ensayos concretos completaría la justificación su superioridad sobre el mero acercamiento estilístico al permitirnos comprender de manera integral la interacción entre estilo y argumentación en el análisis y producción de textos ensayísticos.

\section{La nueva retórica y la retórica del ensayo hispanoamericano}

El análisis de la argumentación en el ensayo escrito en español ha recibido hasta ahora muy poca atención. Con las notables excepciones de los trabajos de Houvenaghel sobre la retórica argumentativa en el ensayo histórico de Alfonso Reyes y los estudios de Alonso acerca de la retórica parlamentaria de Rodó, es difícil encontrar investigaciones que se ocupen primordialmente de la argumentación ensayística. ${ }^{8} \mathrm{El}$

${ }^{8}$ La tesis de Houvenaghel, Alfonso Reyes y la Historia de América. La argumentación del ensayo histórico: un análisis retórico, de 2003 y el análisis de los discursos parlamentarios de 
desinterés por el tema en los análisis críticos tal vez se comprenda mejor si se tiene en cuenta que hace parte de un olvido aún mayor: el de la forma del género en beneficio exclusivo de su temática. Houvenaghel (2003) declara al respecto que "...la crítica tiende, claramente, a inclinarse a favor de los contenidos ideológicos del ensayo, en detrimento de los valores expresivos del mismo y, por lo general, rehúsan, además, vincular los aspectos formales del texto ensayístico con su mensaje ideológico" (p. 526). La ausencia de análisis argumentativos contrasta como lo veremos enseguida con las opiniones que declaran la innegable dimensión argumentativa del ensayo y la pertinencia de la nueva retórica para su estudio.

La calidad argumentativa del ensayo se explica de diferentes maneras en la tradición crítica hispánica. Por ejemplo, Lagmanovich (1984) tiene en cuenta las funciones comunicativas que desempeña el ensayo hispanoamericano siguiendo el modelo de Roman Jakobson, entre las que se destacan para nuestro propósito la conativa y la dialogal. La primera se manifiesta en los mecanismos con los que el ensayista intenta influir en su lector mientras que la segunda caracteriza la comunicación, o mejor, interacción, entre ensayista y lector (p. 20). La actitud conativa está relacionada con la "vertiente persuasiva del ensayo" y se manifiesta a través del uso de la metáfora en los periodos romántico-positivista y naturalista-modernista, mientras que para las vanguardias y el existencialismo, la valoración del otro "tiende a realizarse mediante la argumentación, el razonamiento e inclusive la polémica" como sucedería en el caso de Borges, Sábato y Murena (p. 21). ${ }^{9}$ Por su parte, la actitud dialogal consiste en la consideración

\footnotetext{
Rodó hechos por Alonso en José E. Rodó: una retórica para la democracia de 2009 se inspiran como nosotros de los trabajos de Perelman, pero a diferencia de nuestro estudio, aquellos analizan diversos aspectos de la retórica que nosotros hemos dejado de lado para concentrarnos exclusivamente en la argumentación.

${ }^{9}$ La historia del ensayo puede dividirse en varios momentos. El primero corresponde al de las generaciones de 1837, 1852 y 1867. Los escritores representativos son Sarmiento, Bilbao, Montalvo y Hostos. Se trataría de un periodo "romántico-positivista" (Lagmanovich, 1984, p. 19). El segundo periodo comprende las generaciones de 1882, 1897 y 1912. Sus representantes son Paul Grossac, Martí, Sanín Cano, Rubén Darío, Rodó, Ingenieros, Vasconcelos y Reyes. Este sería el periodo "naturalista-modernista" (p. 19). El tercer periodo abarcaría las generaciones de 1927, 1942 y 1957. Sus autores más importantes son Mariátegui, Martínez Estrada, Borges, Sábato, Zea, Paz, Murena, Fuentes, Cabrera Infante y Fernández Retamar. Este es el momento "vanguardista-existencialista” del ensayo hispanoamericano (p. 19). Desafortunadamente como sucede con muchas de las referencias históricas al ensayo, estas no incluyen estudios del final del siglo XX y XXI.
} 
implícita del interlocutor. Esta consideración de la audiencia, similar a la de los auditorios en la nueva retórica, se expresa en la "actitud programática" del ensayo romántico-positivista que busca convocar al público a la realización de "empresas comunes" (p. 21). En el ensayo naturalista-modernista el diálogo se individualiza debido a que el punto de partida del ensayista es una "concepción subjetiva (intrapersonal, no interpersonal) de la Historia" (p. 22). Y en el ensayo vanguardistaexistencialista la visión trágica y desesperanzada de la Historia se manifiesta mediante programas dirigidos a audiencias específicas y a áreas particulares de la cultura y no a su totalidad (p. 22).

$\mathrm{Si}$ el reconocimiento de una función persuasiva y de una consideración del interlocutor coincide con nuestra perspectiva, debemos sin embargo insistir en la complejidad y flexibilidad de las estrategias argumentativas a las que apela un orador en función de los diversos tipos de auditorios a los que se dirige. Por lo tanto, no estamos necesariamente de acuerdo con la periodización del ensayo presentada aquí puesto que agrupa movimientos con tendencias opuestas como el romanticismo y el positivismo, además de fijar a priori diferentes estrategias retóricas para cada periodo que excluyen a la argumentación propiamente dicha del desarrollo de la Historia del género anterior a la vanguardia. Creemos que en lugar de partir de dicha generalización sería necesario apoyar tales clasificaciones con análisis de textos de cada época, cosa que Lagmanovich no lleva a cabo.

Loveluck (1984) establece otra relación entre ensayo y argumentación a partir del contexto político de Iberoamérica. Afirma que el ensayo en esta región posee un carácter instrumental y persuasivo: "El ensayista de esos países (...) pone su ideología y sus artes suasorias para servir a una causa dada. Por las condiciones continentales, $h a$ de producir un texto comprometido con la denuncia o ha de explorar nuestras necesidades más urgentes" (p. 37). Frente a afirmaciones de este tipo debemos sumarnos a la crítica de Houvenaghel mencionada líneas antes: las posiciones que privilegian ciertos contenidos ideológicos olvidan que el ensayo, no solamente el de Iberoamérica sino el género, se puede ocupar de cualquier tema que le sirva de excusa para reflexionar sobre la cultura y subordinan el problema de la forma a sus compromisos 
políticos sacrificando de paso el carácter crítico y escéptico que la mayoría de los teóricos mencionados hasta aquí señalan de manera casi unánime.

El ensayo privilegia las estructuras "expositivo-argumentativas" en lugar de las "descriptivo-narrativas", rasgo que comparte con "el discurso forense, el sermón, la columna periodística de opinión, etc." (Mignolo, 1984, p. 55). Se trata de un género con una “...intencionalidad reflexivopersuasiva" (Casas, 2010). El cumplimiento de esta intencionalidad se logra mediante distintas estrategias entre las cuales destaca "...la de una traslación mayéutica al lector de la responsabilidad meditativa y/o argumentativa..." (Ibíd.). El lector evalúa las tesis y argumentos de una manera "activa y crítica" que constituye una de las "condiciones pragmáticas" del ensayo de la que carecen la didáctica y el proselitismo (Ibíd.). La intencionalidad persuasiva y reflexiva del ensayo hace de la argumentación uno de sus elementos indispensables. La complicidad en el examen crítico de las conclusiones y argumentos presentados en el texto implica una lectura que cuestiona lo dicho comparable al papel de los participantes en un diálogo socrático (Ibíd.).

Desde el punto de vista histórico, Casas ve en el diálogo socrático el antecedente remoto del ensayo y propone una lista que incluye también a "...el texto doctrinal, las modalidades oratorias, el prólogo, la glosa crítica, la literatura paremiológica y gnómica, las doxografías, la miscelánea, la silva divulgativa, la biografía o la epístola..." que tienen en común una forma expositivo-argumentativa (Ibíd.). Por su parte, Claudio Maíz (2004) ve en las colecciones medievales de ejemplos y sentencias su antecedente inmediato en cuanto técnicas de persuasión que ya habían sido estudiadas por Aristóteles como “...historias insertas a modo de testimonio..." y síntesis de sabiduría que orientan la opinión y la acción (p. 63). Frente a estas especulaciones creemos prudente no confundir ensayo y argumentación. El ensayo posee una dimensión argumentativa. Pero esto no significa que todo género histórico con igual finalidad sea un proto-ensayo sino que se trata de textos con rasgos comunes, tal como lo señala Mignolo.

A pesar de la observación anterior, Maíz enlaza el destino del ensayo al del diálogo socrático. De esta manera, la relación que sostienen 
el ensayo y la argumentación también puede entenderse desde una perspectiva dialéctica gracias a la transferencia de la estructura del diálogo socrático al ensayo moderno. En el diálogo socrático se dan los procedimientos de síncrisis y anácrisis. El primero consiste en la confrontación de diferentes alternativas a una cuestión en la búsqueda de la verdad teniendo en cuenta la capacidad de examen del interlocutor, mientras que el segundo consiste en la provocación del interlocutor para que opine sobre el asunto debatido (p. 59). El ensayo conserva estos procedimientos dialécticos a la vez que sustituye "...la presencia de la plurivocidad de voces de los personajes que representan el diálogo, por la interiorización de la matriz dialógica en la voz autorial" permitiendo el juego y la exploración de varios acercamientos a su objeto (p. 60). Nosotros pensamos que si bien el diálogo puede ser un antecedente del ensayo es posible dar cuenta de su carácter crítico y del modo en que interpela al auditorio sin necesidad de la analogía con la mayéutica socrática. Si partimos de la noción de auditorio de la nueva retórica es posible explicar esa pluralidad de voces de la que habla Maíz. Lo anterior debido a que la idea de auditorio particular incluye a todos los posibles receptores del discurso entre los que también se incluyen el orador mismo en la deliberación personal y el otro en el diálogo (Perelman,1977, p. 32). De otro lado, la consideración de diferentes puntos de vista por parte del orador es una forma de interpretar el imperativo retórico de adaptación a la audiencia sin el cual aquel puede ver su opinión objetada o incluso refutada al no haber considerado de antemano al destinatario de su discurso.

Maíz también señala que el ensayo y la retórica tratan de la opinión probable en lugar de pretender un conocimiento científico necesario y universal: "El discurso ensayístico, al igual que el modelo retórico, se funda en lo verosímil y no en la verdad." (p. 70). Su punto de vista se acerca al de Arenas Cruz y al nuestro cuando indica que ambos poseen una organización equivalente: "La estructura argumentativa del ensayo muchas veces se organiza conforme a las operaciones previstas por la retórica, en virtud de las cuales pone en relación los hechos de los que se ocupa, las verdades de las que parte y las presunciones admitidas" (pp. 107-108). 
Paredes (2008) por su parte nos dice que la retórica antigua estudiaba la oratoria como persuasión, evaluando el discurso tanto por su veracidad como su ornamentación (p. 31). El ensayo y la oratoria coinciden en tanto se dirigen al foro, al público no especializado al que intentan persuadir combinando "su esencia argumentativa con una calidad expresiva" (p. 32). Teniendo en cuenta esta consideración sobre la naturaleza mixta de la retórica, es posible separarla en sus dos elementos constituyentes: una "lógica" que estudia el razonamiento y otra, los "estudios literarios" que corresponden al estudio de los recursos y cualidades de la expresión (pp. 32-33). La retórica del ensayo consistiría en el estudio de estos dos elementos, la argumentación y la expresividad. (p. 33) De este modo, las similitudes entre retórica y ensayo nos permiten entender la argumentación en este género, pero no resuelven su ambigüedad: "La estructura argumentativa del ensayo constituye la bisagra que reúne el ordenamiento más o menos sistemático del pensamiento, por lo que se acerca al discurso teorético, pero la preocupación por la dispositio y la elocutio de las estructuras retóricas, lo proyecta hacia la noción artística" (Maíz, 2004, p. 110). ${ }^{10}$

Finalmente, de Obaldía (1995) señala la ambigüedad del ensayo que lo deja a medio camino entre filosofía y literatura, sintetizada por él del siguiente modo:

.... On the one hand, the form of the essay makes it a member of literature and does, for some theorists, grant it the right to establish itself as a fourth literary genre alongside the other three. On the other hand, the content of essay, the fact that it is concerned with ideas ultimately addressed directly by an author to a reader, assigns the genre primarily to the category of didactic, expository, of critical writing. In so far as 'the

\footnotetext{
${ }^{10} \mathrm{~A}$ propósito de esta ambigüedad, Maíz anota lo siguiente: "Dos referencias principales definen la genealogía del discurso ensayístico: una, directamente vinculada con el antiguo género del "diálogo socrático"; otra, el modelo de producción retórica que se manifiesta en la estructura argumentativa. Del primero, proceden tanto la actitud dialógica del género, es decir, la incorporación del destinatario en la conformación del texto, como el procedimiento discursivo. A su vez, de ahí se desprende, en cierto modo, la verbalidad y el tono conversacional. Del segundo, emanan la noción artística en la exposición de ideas - "la palabra ornamentada" de la antigua retórica-, y la estructura argumentativa. Desde un plano filosófico, también, la Retórica provee el componente verosímil -lo que no niega en el ensayo la búsqueda de la verdad, a veces nada más que como búsqueda-, en virtud de ello la unidad ensayística pertenece al ámbito de la doxa" (Maíz, 2004, p. 111).
} 
essay's essential quality is persuasion', in so far as 'in its purest form, it is an argument', the aesthetic organization of the material remains subordinated to the treatment of an event or situation that exists in time and space, of an idea or text which the essayist is ultimately committed to telling the 'truth' about, a truth which he himself is answerable for. The result of this conflict between form and content is that the essay 'goes unrecognized either as knowledge or as art. From the point of view of science or philosophy, the essay is too 'artistic', too concerned with the strategies of writing itself; yet this does not suffice boldly to admit the genre into the realm of so-called creative or imaginative literature". (p. 5)

Nosotros creemos que las posiciones de Maíz, Paredes y de Obaldía reposan en distinciones del tipo fondo versus forma, medio versus fin, literatura versus ciencia-filosofía, que hacen imposible encontrarle lugar a un género híbrido como el ensayo. Este debate está lejos de zanjarse y a propósito nos preguntamos si esta hibridez dejaría de ser un problema al reemplazar las distinciones que acabamos de mencionar por un sistema que le diera su lugar propio a la retórica y a otros discursos como, por ejemplo, el político, el judicial, el periodístico o el publicitario, al lado de la literatura y la ciencia. Al hacerlo, le abriríamos un lugar al ensayo, pero también a otros géneros de intención persuasiva y procederes argumentativos que son mejor explicados por la retórica en tanto teoría de la argumentación y lógica de los juicios de valor, tal como lo propone Perelman, restableciéndole además al estilo y a la composición su dimensión argumentativa y no meramente ornamental que, dicho sea de paso, hace de la literatura un estudio del estilo separado de la reflexión. A esta categoría, que podría ser la de los géneros retóricos, tendrían acceso los textos y discursos políticos, periodísticos, morales, estéticos y jurídicos que en el modelo binario acceden sólo parcialmente al estatuto artístico, pero a costa de abandonar su utilidad y vigencia. 


\section{Conclusión:}

Nuestro estudio no pretende definir, de una vez por todas, la naturaleza del ensayo y zanjar la eterna disputa acerca de este género. Únicamente nos interesa presentar un nuevo acercamiento retórico al ensayo que revalora su argumentación y llamar la atención sobre el estudio de sus tipologías textuales inspiradas en la nueva retórica que ponen de manifiesto la importancia de la argumentación como criterio para definir la tarea reflexiva del ensayo y distinguirlo de otras formas afines como el manifiesto y el panfleto. También, señalar que la aplicación de la nueva retórica al estudio de la construcción textual del ensayo por parte de investigadores como Arenas Cruz resalta claramente su finalidad persuasiva, a la que corresponde necesariamente una estructura textual y estilística centrada en la argumentación. Este hecho es corroborado y ampliado con el estudio de las opiniones sobre la argumentación en la teoría del ensayo hispanoamericano que, a pesar de no haber producido todavía estudios sobre textos concretos, reconocen el papel central de la argumentación en el ensayo. La comprensión de la estructura y funciones argumentativas del ensayo, tanto como las ventajas que para ello presenta una retórica centrada en la argumentación y no en el estilo, puedan tal vez ser la clave para un estudio de ensayos y ensayistas en español y, por qué no, de una nueva comprensión de la literatura ensayística y del pensamiento hispanoamericanos. 
Andrés Felipe Peralta Sánchez

\section{Bibliografía}

Alonso, D. (2009). José E. Rodó: una retórica para la democracia. Montevideo: Trilce.

Arenas Cruz, M. E. (1997). Hacia una teoría general del ensayo: construcción del texto ensayístico. Cuenca: Ediciones de la Universidad de Castilla-La Mancha.

Casas, A. (2010).Breve propedéutica para el análisis del ensayo. Proyecto ensayo hispánico. Recuperado de http://www.ensayistas.org/critica/ ensayo/casas.html.

de Obaldía, C. (1995).The Essayistic Spirit: Literature, Modern Criticism, and the Essay. Oxford; New York: Clarendon Press; Oxford UP.

Dumont, F. (2003). Approches de l'essai. Anthologie. Québec: Nota bene.

Houvenaghel, E. (2003). Alfonso Reyes y la historia de América. La argumentación del ensayo histórico: un análisis retórico. México: Fondo de cultura económica.

(2002). "La hegemonía de la temática sobre la forma en el estudio del ensayo hispanoamericano." Revista de literatura: LXIV, 128, 525-537.

Lagmanovich, David. (1984). Hacia una teoría del ensayo hispanoamericano. Loveluck, J. y Lévy. I. (eds.). Simposio el ensayo hispánico: actas (pp. 1728). Columbia, S.C.: U. of South Carolina Press.

Loveluck, J. (1984). Esquividad y concreción en el ensayo. Loveluck, J. y Lévy. I. (eds.). Simposio el ensayo hispánico: actas. (pp. 29-43). Columbia, S.C.: South Carolina UP, 1984.

Maíz, C. (2004). El ensayo: entre género y discurso. Debate sobre el origen y funciones en Hispanoamérica. Mendoza: Editorial de la Facultad de Filosofía y Letras de la Universidad del Cuyo.

Meyer, M. (1991). Introduction. Rhétorique d'Aristote. Trad. de C.E. Ruelle. Paris: Librairie Générale Française.

Mignolo, W. (1984). Discurso ensayístico y tipología textual. Loveluck, Loveluck, J. y Lévy. I. (eds.). Simposio el ensayo hispánico: actas. (pp. 45-61) Columbia, S.C.: South Carolina UP.

Ospina, W. (2003). La herida en la piel de la diosa. Bogotá: Aguilar. Américas.

(2001). Los nuevos centros de la esfera. La Habana: Casa de las

Paredes, A. (2008). El estilo es la idea: ensayo literario hispanoamericano del siglo XX. México: Siglo XXI.

Perelman, Ch. (1977). L'Empire rhétorique: Rhétorique et argumentation. Paris: Vrin.

(1991). "Pierre de La Ramée et le déclin de la rhétorique." Argumentation, 5(4), 347-356. 
Poligramas 41 - diciembre de 2015 Bruxelles.

Rhétoriques. (1989). Bruxelles: Éditions de l'Université de

Perelman, Ch. y Olbrechts-Tyteca, L. (2000). Traité de l'argumentation: la nouvelle rhétorique. $5^{\text {a }}$ edición. Bruxelles: Éditions de l'Université de Bruxelles.

Toulmin, S. E. (2003). The Uses of Argument. Cambridge: Cambridge UP. 